Original article

\title{
Hepatitis B: Epidemiology and prevalence in Iran, during 2002-2014
}

\author{
Farhood Nikouee ${ }^{1}$, Mitra Soltanian², Alireza Safari, Mohadeseh Motamed-Jahromi*
}

(Received: 25 Mar 2016; Accepted: 24 May 2016)

\begin{abstract}
Background and Purpose: Hepatitis B is a major health problem around the globe the prevalence of which varies depending on the region and study. In this study, we aimed to determine the epidemiology and prevalence rates of hepatitis B in Fasa, Iran.

Methods: This descriptive, cross-sectional study was performed using medical records of all the hepatitis B patients referring to Fasa Health Center during 2002-2014. The demographic variables and other required data were obtained and recorded, and then descriptive statistics (frequency, mean, and percentage) were reported using SPSS, version 18.

Results: In this study, from the 208 patients, $83.2 \%$ were male, and $83.2 \%$ were aged between 21 and 30 years. The majority of the hepatitis B patients (97.1\%) did not have history of vaccination against the disease. The number of addicts using intravenous injection and suffering from hepatitis B was higher (31.7\%) than others. The prevalence rate of this disease was $0.01 \%$ in 2014 .

Conclusion: The prevalence and incidence of hepatitis B in 2014 in Fasa indicate the necessity of prevention and vaccination for those at high risk of the disease. Health education programs in schools, universities, organizations, and even mosques can play a major role in preventing the prevalence of the disease.
\end{abstract}

Keywords: Epidemic, Epidemiology, Hepatitis B, Intravenous drug abuse

\section{Introduction}

Hepatitis $\mathrm{B}$ is one of the most important health problems all over the world with serious socioeconomic impacts on the whole world (1). Epidemiology of this disease shows that at least 350 million people suffer from hepatitis, and annually one million people die of cirrhosis and hepatocellular carcinoma (2). The prevalence of hepatitis B in different regions range from $1 \%$ to $20 \%$ (3).

The prevalence of hepatitis B in Iran over the past two decades has been almost 3.2\%. Iran has faced the intermediate prevalence of hepatitis B infection, where the risk of suffering from this disease is 20$60 \%$ (4). The prevalence of hepatitis B in the Iranian population during the past decade has decreased (5). Increased awareness regarding the risk factors for hepatitis and establishment of an international vaccination program in 1993 for all high-risk individuals, especially health employees and infants,

\footnotetext{
${ }^{1}$ Department of Community Medicine, Fasa University of Medical Sciences, Fasa, Iran

${ }^{2}$ School of Nursing and Midwifery, Shiraz University of Medical Sciences, Shiraz, Iran

${ }^{3}$ Fasa University of Medical Sciences, Fasa, Iran

4,* Corresponding author: School of Nursing, Fasa University of Medical Sciences, Fasa, Iran. Email: mohadesehmotamed@yahoo.com
} 
account for the reduced hepatitis epidemic spread (6). Nowadays, the $1.7 \%$ prevalence of the disease in Iran is considered low-spread. Despite the use of vaccines against hepatitis $B$ in the past four decades and a significant reduction in the prevalence of hepatitis $\mathrm{B}$, the disease is still prevalent, which is due to low rates of diagnosis and treatment and the reluctance of people to vaccination, even in advanced countries (7).

A study showed that seroprevalence of HBsAg in Iran increased from about $3.5 \%$ in 1990 to $14.2 \%$ in 2003-2008 (8). In Sistan and Baluchestan and Fars provinces, the prevalence rates of the disease ranged between $5 \%$ and $1.7 \%$ (9). The prevalence of hepatitis B among blood donors 11 days after Bam earthquake in Iran in 2003 was $0.45 \%$ (10). The prevalence of chronic HBsAg carrier state in family members of patients was five times higher than the rest of population, which may be due to transmission of infection in close familial contacts (11). Another study exhibited that the prevalence of this disease among truck drivers was $5.9 \%$ in 2003, which was higher than people with other occupations (12).

In Iran, few studies have considered hepatitis B, especially over the past few years. Given the importance of prevention of this disease in different populations and lack of epidemiological knowledge on the prevalence and risk factors for hepatitis in Fasa, this study aimed to study its epidemiology and epidemic percentage based on the demographic and geographical characteristics of hepatitis B patients in Fasa. This study can help take the required measures to prevent hepatitis B by determining its risk factors and epidemic and epidemiological probability.

\section{Materials and Methods}

This descriptive, cross-sectional study was performed using medical records of all patients infected with hepatitis B referring to Fasa Health Center, during 2002-2014. Convenient sampling method was used and the patients' incomplete profiles were completed through contacting them via phone calls. A total of 208 patients were studied; the inclusion criteria comprised of being identified in their medical records at the health center of Fasa University of Medical Sciences as having hepatitis $\mathrm{B}$ virus (HBV) during 2002-2014.

The demographic information form including age, gender, educational level, occupation, place of residence, history of incarceration, intravenous drug abuse, unsafe sexual contact, and tattooing, as well as epidemiological and clinical information (i.e., history of contact with a hepatitis patient, family history, history of vaccination against hepatitis, blood transfusion history, date of onset of symptoms, and treatment outcome) were completed by one of the researchers based on patient records. The collected data were analyzed, and mean, standard deviation, and median were reported, using SPSS version 18.

\section{Results}

In this study, 208 patients with mean age of $35 \pm 19.46$ years were studied during 2002-2014. Among the patients, 173 patients were male (83.2\%) and 35 female (16.8\%). A total of 153 participants were married $(73.6 \%)$. In terms of geographical location, 125 individuals $(60.1 \%)$ lived in urban areas; $83.2 \%$ of the subjects were aged between 21 and 30 years. The incidence of hepatitis B in the city of Fasa increased during the study period (Figure 1).

The risk of exposure to the disease for blood product recipients, addicts who used injection, patients who had unsafe sexual contact, and those receiving beauty services and skin-penetrating procedures such as tattoos were $6.3 \%, 31.7 \%$, $26 \%$, and $14 \%$, respectively. The majority of the patients with hepatitis B (97.1\%) did not have history of vaccination against the disease. Those who were vaccinated $(2.9 \%)$ did not go through all the three phases of vaccination. No patient had the experience of full hepatitis B vaccination. Moreover, 101 (48.6\%) patients had diploma, 49 (23.6\%) had finished high school, 36 (17.3\%) elementary school, 11 (5.3\%) had Bachelor's degree, and 11 $(5.3 \%)$ were illiterate. According to the results, the prevalence of hepatitis B in Fasa in 2014 was $0.01 \%$ (Figure 2). 


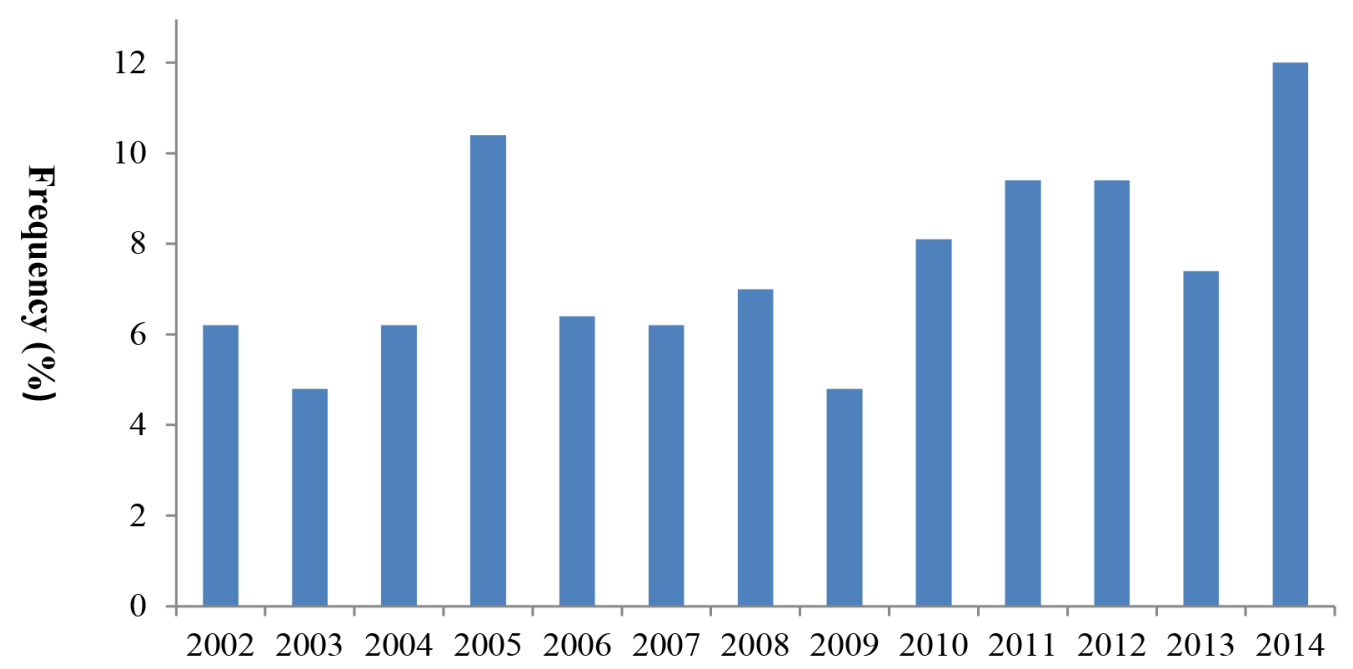

Figure 1. Incidence rates of hepatitis B in Fasa during 2002-2014

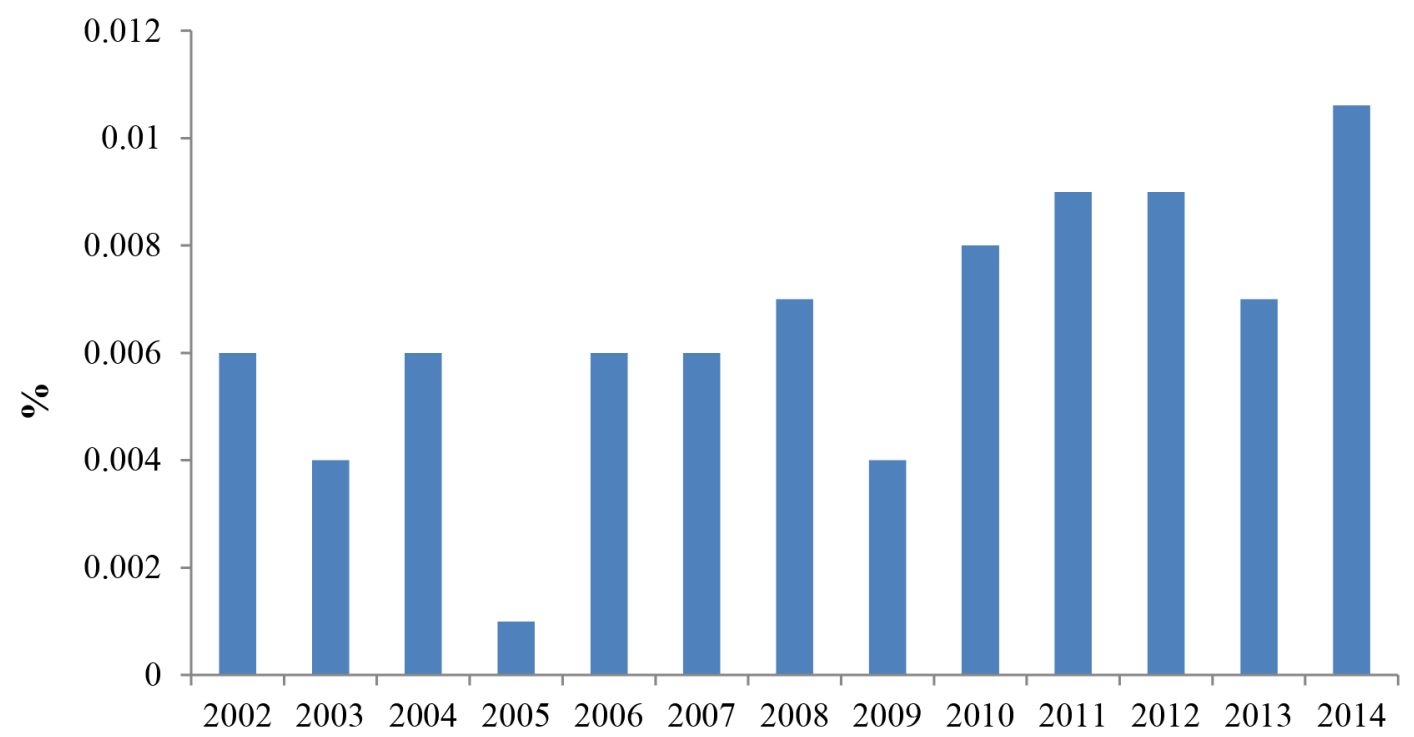

Figure 2. Prevalence of hepatitis B in Fasa during 2002-2014

\section{Discussion}

Hepatitis B is a highly prevalent disease around the globe and is considered as a health care problem in many countries including Iran. In this study, the prevalence of hepatitis B in Fasa in 2014 (0.01\%) is reported to be on a growing trend compared to the previous years. The prevalence of this disease in Fasa was lower compared to its prevalence rate in Iran (1.7\%). The overall prevalence of the disease varies depending on the region, population, and the frequency of risk factors in that region.
Our findings revealed that prevalence of hepatitis $\mathrm{B}$ was higher in males than in females. In a study carried out by Ghenaat et al. between 1998 and 2000, the prevalence of serum levels of HBsAg in females and males were $10 \%$ and $14.2 \%$, respectively (13). Another study showed equal involvement of females and males with hepatitis B in Khorasan province, Iran (14). Hepatitis B infection can be more prevalent in males as they are more likely to be tattooed use drug injection, and have unsafe sexual relations. Men are also more prone to trauma, and 
thus, they are more exposed to blood transfusion.

Men pay less attention to their health than women do, and therefore, they are more prone to disease than women are. Our findings also pointed out that the highest prevalence rate of hepatitis B was found in the 21-30 years age group, while in a study performed in Turkey, the highest prevalence was in the age group between 41 and 50 years (15). In another study in Isfahan, the highest frequency was reported for those aged between 40 and 49 years (16). In a national study, the highest prevalence of hepatitis B was reported in the age group between 40 and 49 years (17). As expected, the infection rate in the age group below 20 years was low, which was due to good coverage and effectiveness of immunization in this age group, which was confirmed by other studies suggesting that infection rate is low in patients aged less than 20 years due to high vaccination coverage (Table 1 ).

According to the findings, married people are at higher risk of infection compared to single people. Although our results do not determine the original pattern of disease transmission, higher rates of infection in married cases shows that sexual intercourse plays a significant role in HBV transmission. The low rate of infection in single individuals is also due to their low age and high coverage of vaccination in this population.

According to the results, the percentage of patients living in urban areas was approximately one and half times higher than those living in rural areas, which could be simply due to higher risk factors for HBV and earlier diagnosis of the disease because of having easier access to laboratories and health centers in cities than rural areas.

Table 1. Age group of the patients with hepatitis B in Fasa during 2002-2014

\begin{tabular}{lcc}
\hline Age (yr) & Frequency (n) & Frequency (\%) \\
\hline $11-20$ & 1 & 0.5 \\
$21-30$ & 74 & 35.5 \\
$31-40$ & 55 & 26.4 \\
$41-50$ & 46 & 22.1 \\
$51-60$ & 26 & 12.5 \\
$61-70$ & 3 & 1.5 \\
$71-80$ & 3 & 1.5 \\
\hline Total & 208 & 100 \\
\hline
\end{tabular}

During a 13-year period, the highest percentage of infection was in people not receiving complete hepatitis B vaccination (97.1\%), which indicates the importance of complete vaccination. In a study conducted between 2000 and 2002 on Iraqi children (families under the supervision of Mosel Public Health Institute, 744 children who were born between 1994 and 1998 were identified as carriers of hepatitis B. Meanwhile, 12 children were not vaccinated due to their parents' lack of interest and others had not completed the vaccination (18).

In the current study, the infected individuals were categorized based on infection form into the following groups: drug injection, sexual intercourse, receiving beauty services and skin-penetrating procedures such as tattoos, no clear reason, the existence of the disease in family members, and blood transfusion. According to the findings, the majority of those who were intravenous drug users were infected with chronic hepatitis B due to sharing one needle for injection. In Pakistan, a country which is encountering the growing endemic of hepatitis $\mathrm{B}$ and $\mathrm{C}$, reuse of needles was identified as an important factor for these infections (19).

Risk factors for those suffering from hepatitis B included low age, non-nativity, and living outside urban areas. According to this study, living in endemic areas and out of cities expose younger people to hepatitis B. Another study reveals that migrating workers, smokers, and non-native citizens of southern Lebanon were more exposed to hepatitis B (20). Another study found that tattooing and phlebotomy were the most frequent behaviors among migrators, which increased the risk of infection (21). During all the 13 years, the infection rates were the lowest and highest in 2003 (10 people) and 2014 (25 people), respectively. The growing trend of HBV infection in the recent years might be due to the improvement of facilities and instruments for disease diagnosis.

\section{Conclusion}

Paying attention to epidemiology of hepatitis B in different regions is practically important in prevention and treatment of the disease. Since the incidence and 
prevalence of the disease in Fasa was on a growing trend over the past few years, several programs should be developed for prevention, treatment, and vaccination of all people. Measures such as free distribution of disposable syringes for drug injection to addicts can be helpful in preventing disease transmission.

Health education programs in schools, universities, organizations, and even in mosques can play a fundamental role in informing and sensitizing people about the disease and preventing its spread in the society. Given the findings of the present study, further studies are suggested to identify the details of risk factors, environmental conditions, and physical and personal characteristics of the infected individuals such as personal features, psychological state, behaviors, social character, and comorbidities. Detection of the disease risk factors may lead to establishment of a creative intervention for preventing the disease and reducing the financial costs and mortalities caused by hepatitis B.

\section{Conflicts of interest}

None declared.

\section{Authors' contributions}

F. Nikouee was the chief investigator and principal author of the manuscript. M. Motamed-Jahromi was responsible for preparation of the final manuscript. M. Soltanian proposed the study subject. A. Safari performed data collection.

\section{Acknowledgments}

This article was extracted from a research project approved by the Deputy of Research at Fasa University of Medical Sciences. We wish to thank those who assisted us to perform this study.

\section{References}

1. Voiculescu M. How far we are towards eradication of HBV infection. J Gastrointestin Liver Dis 2015; 24(4):473-9.

2. World Health Organization. Guidelines for the prevention, care and treatment of persons with chronic hepatitis B infection. Geneva: World Health Organization; 2015.
3. Lavanchy D. Hepatitis B virus epidemiology, disease burden, treatment, and current and emerging prevention and control measures. J Viral Hepat 2004; 11(2):97-107.

4. Alavian SM, Fallahian F, Lankarani KB. The changing epidemiology of viral hepatitis B in Iran. J Gastrointestin Liver Dis 2007; 16(4):403-6.

5. Zarban A, Malekinejad P, Akhbari H. Evaluation of HGV viremia prevalence and its co-infection with $\mathrm{HBV}, \mathrm{HCV}$, HIV and HTLV-1 in hemophilic patients of Southern Khorassan, Iran. Hepat Mon 2007; 7(1):11-4.

6. Alavian SM. Ministry of Health in Iran is serious about controlling hepatitis B. Hepat Mon 2007; 7(1):3-5.

7. Feldman M, Friedman LS, Brandt LJ. Sleisenger and Fordtran's gastrointestinal and liver disease: pathophysiology, diagnosis, management. New York: Elsevier Health Sciences; 2015.

8. Alavian SM, Hajarizadeh B, Ahmadzad-Asl M, Kabir A, Bagheri-Lankarani K. Hepatitis B Virus infection in Iran: a systematic review. Hepat Mon 2008; 8(4):281-94.

9. Merat S, Malekzadeh R, Rezvan H, Khatibian M. Hepatitis B in Iran. Arch Iran Med 2000; 3(4):192-201.

10. Bozorgi S, AhmadzadAsl M, Ramezani H, Kargarfard H, Alavian S. Study of viral infections prevalence in blood donors of Qazvin province in different time intervals and during Bam earthquake. Govaresh 2006; 11(4):242-8.

11. Hatami H, Salehi M, Sanei E, Khosravi S, Alavian SM. Intra-familial transmission of hepatitis B virus infection in Zahedan. Iran Red Crescent Med J 2013; 15(1):4-8.

12. Jahani MR, Motevalian SA, Mahmoodi M. Hepatitis B carriers in large vehicle drivers of Iran. Vaccine 2003; 21(17):1948-51.

13. Ghanaat J, Sadeghian A, Ghazvini K, Nassiri MR. Prevalence and risk factors for hepatitis B virus infections among STD patients in northeast region of Iran. Med Sci Monit 2003; 9(2):CR91-4.

14. Farhat A, Khademi G, Mazlouman SJ. The prevalence of hepatitis B carrier state in Khorassan province of Iran. Saudi Med J 2003; 24(5):549-51.

15. Ucmak H, Faruk Kokoglu O, Celik M, Ergun UG. Intrafamilial spread of hepatitis B virus infection in eastern Turkey. Epidemiol Infect 2007; 135(8):1338-43.

16. Nokhodian Z, Kassaian N, Ataei B, Javadi AA, Shoaei P, Farajzadegan Z, et al. Hepatitis B markers in Isfahan, Central Iran: a population-based study. Hepat Mon 2009; 9(1):12-6.

17. Zali MR, Mohammad K, Noorbala AA, Noorimayer B, Shahraz S. Rate of hepatitis B seropositivity following mass vaccination in the Islamic Republic of Iran. East Mediterr Health J 2005; 11(1-2):62-7.

18. Ali HY. Hepatitis B infection among Iraqi children: the impact of sanctions. East Mediterr Health J 2004; 10(12):6-11.

19. Janjua NZ, Hutin YJ, Akhtar S, Ahmad K. Population beliefs about the efficacy of injections in Pakistan's Sindh 
province. Public Health 2006; 120(9):824-33.

20. Saab BR, Nassar NT, Musharrafieh U, Araj GF, Khogali M. Prevalence of hepatitis B in a presumably healthy Lebanese population. J Med Liban 2006; 55(1):11-4.
21. Hosseini Asl SK, Avijgan M, Mohamadnejad M. High prevalence of HBV, HCV, and HIV infections in Gypsy population residing in Shahr-E-Kord. Arch Iran Med 2004; 7(1):20-2. 